\title{
Effect of pressure-relief ducts on traction demand in a tunnel: a numerical evaluation
}

1 Sang Yeon Seo PhD

Research Engineer, GS Engineering \& Construction, Seoul, South Korea
2 Heesang Ha PhD

Principal Research Engineer, GS Engineering \& Construction, Seoul, South Korea (corresponding author: hsha@gsenc.com)
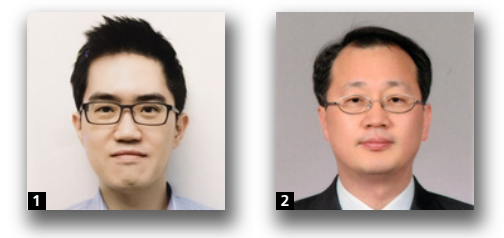

High-speed trains are one of the most desirable and environmentally friendly transportation modes, and high-speed rail has been widely implemented in European and Asian countries in order to transport vast quantities of people and commodities rapidly. However, when a high-speed train enters a tunnel, aerodynamic resistance is generated suddenly, which results in higher traction power demand for trains operating in tunnels. It is essential to incorporate pressure-relief systems in tunnels to reduce the aerodynamic resistance caused by passage of a high-speed train. Pressure-relief ducts and vertical shafts are the most commonly used pressure-relief measures in tunnels. The effect of pressure-relief ducts to alleviate the aerodynamic resistance and reduce traction power demand of high-speed trains was thus investigated by means of one-dimensional numerical simulations of various case studies.

\author{
Notation \\ $A_{\text {ann }} \quad$ area of annulus between train and tunnel $\left(\mathrm{m}^{2}\right)$ \\ $A_{\mathrm{T}} \quad$ free cross-sectional area of tunnel $\left(\mathrm{m}^{2}\right)$ \\ $A_{z} \quad$ cross-sectional area of train $\left(\mathrm{m}^{2}\right)$

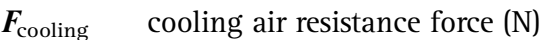 \\ $\boldsymbol{F}_{\text {friction }} \quad$ drag force due to longitudinal friction (N) \\ $\boldsymbol{F}_{\text {lin }} \quad$ linear resistance force $(\mathrm{N})$ \\ $\boldsymbol{F}_{\mathrm{NT}} \quad$ drag force due to losses at the nose and tail of the \\ train $(\mathrm{N})$ \\ $\boldsymbol{F}_{\text {rolling }} \quad$ rolling resistance force $(\mathrm{N})$ \\ $\boldsymbol{F}_{\mathrm{T}} \quad$ traction force $(\mathrm{N})$ \\ $f_{z} \quad$ skin friction coefficient \\ $k_{\mathrm{N}} \quad$ nose loss coefficient \\ $k_{\mathrm{T}} \quad$ tail loss coefficient \\ $L_{z} \quad$ length of train (m) \\ $l_{z} \quad$ perimeter of train $(\mathrm{m})$ \\ $P_{\mathrm{T}} \quad$ traction power (W) \\ $v_{z} \quad$ velocity of train $(\mathrm{m} / \mathrm{s})$ \\ $v_{\text {ann }}^{*} \quad$ velocity of air in annulus relative to train $(\mathrm{m} / \mathrm{s})$ \\ $\beta \quad$ blockage ratio \\ $\rho \quad$ density of air $\left(\mathrm{kg} / \mathrm{m}^{3}\right)$
}

\section{Introduction}

The demand for fast and secure travel has produced a need for the planning and construction of underground infrastructure for public transport such as high-speed rail. In order to maintain speed, high-speed trains require a track with larger curvature than that needed for low-speed trains and so tunnels are a major part of high-speed rail infrastructure. A large number of high-speed railway projects are due for completion by the end of 2025, with a total length of 0.59 million $\mathrm{km}$ (Yang et al., 2017).

According to Reinke and Busslinger (2011), large aerodynamic resistance is generated when a train enters a tunnel. With the speeds of trains increasing, aerodynamic effects are becoming very important in the design of both tunnels and trains. Aerodynamic resistance increases dramatically with an increase in train speed (Gawthorpe, 1978), with aerodynamic drag accounting for $85 \%$ of the total resistance when train speed increases to $300 \mathrm{~km} / \mathrm{h}$ (Qun-Zhan, 2010). High aerodynamic resistance acting on a train leads to high energy consumption for train operation and has a negative impact on a train's speed increase (Raghunathan et al., 2002). According to Wood (2003), 16\% of the total energy consumed in train operation in the USA is used to overcome aerodynamic drag. Aerodynamics might thus be a determining factor for the size and other design features of highspeed tunnels rather than just the economics of construction.

Several factors are associated with aerodynamic conditions in high-speed railway tunnels. For example, traction power demand should be reduced in the design of locomotives operating in tunnels because a high-speed train running in a tunnel demands much higher traction power than a train running on open track (Henson, 1995). In addition, when a train enters a tunnel, compression and expansion waves are generated in the tunnel (Howe et al., 2000). These rapid pressure changes require that the comfort and health of passengers is guaranteed. Micro-pressure waves can also be generated when a train 
enters and exits a tunnel, which can cause a loud noise at tunnel portals (UIC, 2005). In addition, the speed of air flow in a tunnel needs to be limited since high-speed air can put maintenance workers at risk and damage tunnel equipment. Aerodynamic conditions thus need to be carefully considered in the design stage of a tunnel. These aerodynamic conditions become increasingly important for very long tunnels of over $50 \mathrm{~km}$ (Reinke and Busslinger, 2011). In addition, tunnels accommodating high-speed trains (i.e. more than $200 \mathrm{~km} / \mathrm{h}$ ) and mixed traffic require strict aerodynamic regulations.

Several measures can be taken to limit these adverse aerodynamic aspects, including speed restrictions on rolling stock, enlargement of tunnel cross-sectional area and the installation of pressure-relief devices. There are also a number of different design concepts for high-speed railway tunnels. In the past, tunnels of short or medium length were designed as single-tube, double-track systems. For long tunnels, twin-tube, single-track systems are commonly adopted. A twin-tube, single-track tunnel might experience more extreme aerodynamic conditions since it has a smaller free cross-sectional area than a single-tube, doubletrack tunnel. In order to overcome the extreme aerodynamic conditions in long tunnels, various air pressure-relief measures have been developed. These include enlargement of the free cross-sectional area of a tunnel, installation of a vertical shaft, a crossover tunnel in the middle of twin-tube tunnels, pressurerelief ducts connecting twin tubes and so on. According to the International Union of Railways (UIC, 1998), the various methods to reduce aerodynamic resistance in a tunnel include modification of the tunnel geometry and portal shape, installation of a dividing wall between tunnels and the installation of airshafts for pressure relief (UIC, 1998). Vardy and Dayman (1979) found that the maximum air pressure in a tunnel could be reduced by up to $40 \%$ by the incorporation of vertical airshafts.

The Channel tunnel is the most famous subsea tunnel and is the longest subsea tunnel in the world, with an overall length of $50 \mathrm{~km}$ and an undersea section $38 \mathrm{~km}$ long (Fairbairn, 1995). Each tunnel has a diameter of $7.6 \mathrm{~m}$ and carries passenger and national freight trains. A service tunnel of diameter $4.8 \mathrm{~m}$ lies between the two running tunnels (Southwood, 1994) and the two running tunnels and the service tunnel are connected by cross passages of $3.3 \mathrm{~m}$ dia. or $4.8 \mathrm{~m}$ dia. every $375 \mathrm{~m}$. Pressure-relief ducts of $2 \mathrm{~m}$ diameter are installed every $250 \mathrm{~m}$ between the two running tunnels to alleviate air pressure generated by running trains (Gawthorpe and Pope, 1992). These pressure-relief ducts lead to the exchange of air masses between the running tunnels and thus prevent air pressure from increasing (Barthes et al., 1994). The Channel tunnel thus efficiently manages aerodynamic resistance by these pressure-relief ducts.

Using quasi-one-dimensional (1D) numerical simulations, Mossi and Sibilla (2002) analysed the effects of pressure- relief ducts installed every $5 \mathrm{~km}$ between two tunnels under partial vacuum. Their results showed that pressure-relief ducts decrease both the peak pressure resistance in tunnels and the traction power required for train operation.

Many very long high-speed railway tunnels have been, and will be, constructed in South Korea. As already noted, the aerodynamic conditions prevailing in very long tunnels are a major concern and it is thus important to estimate aerodynamic conditions and evaluate techniques to alleviate the air pressure acting on high-speed trains in very long tunnels (Shen, 2012). In the study reported in this paper, the effect of pressure-relief ducts on high-speed trains was evaluated by means of 1D numerical simulations. Detailed specifications of the pressurerelief system, such as the free cross-sectional area and the distance between ducts, were analysed according to the results of the numerical simulations and traction power demands were calculated for a train passing through a tunnel at speeds of $300 \mathrm{~km} / \mathrm{h}$ and $350 \mathrm{~km} / \mathrm{h}$.

\section{Traction power demand}

Traction power is the power required for the operation of a train. Trains consume power for the operation of various devices such as engines, transformers, air conditioners, pumps and coolers. In order to move and then increase the speed of the train, the required traction power increases significantly in order to overcome resistance against the train's movement. Aerodynamic resistance is thus a significant factor in the power consumption of trains. According to Vardy (1996a, 1996b), aerodynamic drag contributes more than $90 \%$ of the total drag on high-speed trains in long tunnels. In addition, the aerodynamic resistance on a train passing through a tunnel leads to significantly higher traction power requirements than a train running on open track and aerodynamic resistance increases with the speed of the train. It is therefore important to estimate the exact traction power required for a train in the design stage.

Traction power is a function of the traction force and the velocity of the train, as defined by (Reinke and Busslinger, 2011)

$$
\text { 1. } P_{\mathrm{T}}=\boldsymbol{F}_{\mathrm{T}} \boldsymbol{v}_{z}=\left(\boldsymbol{F}_{\text {air }}+\boldsymbol{F}_{\text {rolling }}+\boldsymbol{F}_{\text {cooling }}+\boldsymbol{F}_{\text {lin }}\right) \boldsymbol{v}_{z}
$$

in which $P_{\mathrm{T}}$ is the traction power $(\mathrm{W}), \boldsymbol{F}_{\mathrm{T}}$ is the traction force $(\mathrm{N}), \boldsymbol{v}_{z}$ is the train velocity $(\mathrm{m} / \mathrm{s}), \boldsymbol{F}_{\text {air }}$ is the aerodynamic drag force $(\mathrm{N}), \boldsymbol{F}_{\text {rolling }}$ is the rolling resistance force $(\mathrm{N}), \boldsymbol{F}_{\text {cooling }}$ is the cooling air resistance force $(\mathrm{N})$ and $\boldsymbol{F}_{\text {lin }}$ in the linear resistance force $(\mathrm{N})$.

The rolling resistance force, the cooling air resistance force and the linear resistance force are not influenced by a tunnel (Reinke and Busslinger, 2011). However, the aerodynamic drag force changes when a train enters a tunnel from open track because the train faces different aerodynamic conditions in 
an open space and in the tunnel. Therefore, the aerodynamic drag force is the major factor in estimating the traction power and is defined by

\section{2. $\quad \boldsymbol{F}_{\text {air }}=\boldsymbol{F}_{\mathrm{NT}}+\boldsymbol{F}_{\text {friction }}$}

where $\boldsymbol{F}_{\mathrm{NT}}$ is the drag force due to losses at the nose and tail of the train $(\mathrm{N})$ and $\boldsymbol{F}_{\text {friction }}$ is the drag force due to longitudinal friction $(\mathrm{N})$.

The drag force due to losses at the nose and tail and longitudinal friction can be calculated according to (Reinke and Busslinger, 2011)

$$
\text { 3. } \boldsymbol{F}_{\text {air }}=\left(k_{\mathrm{N}}+k_{\mathrm{T}}\right) \frac{1}{2} \rho\left(\boldsymbol{v}_{\text {ann }}^{*}\right)^{2} A_{\mathrm{T}}+f_{z} \frac{1}{2} \rho\left(\boldsymbol{v}_{\text {ann }}^{*}\right)^{2} l_{z} L_{z}\left(\frac{1}{1-\beta}\right)
$$

where $k_{\mathrm{N}}$ is the nose loss coefficient, $k_{\mathrm{T}}$ is the tail loss coefficient, $\rho$ is the density of air $\left(\mathrm{kg} / \mathrm{m}^{3}\right), v_{\mathrm{ann}}^{*}$ is the velocity of air in the annulus relative to that of the train $(\mathrm{m} / \mathrm{s}), f_{z}$ is the skin friction coefficient, $l_{z}$ is the perimeter of the train $(\mathrm{m}), L_{z}$ is the length of the train (m), $\beta$ is the blockage ratio, $A_{\text {ann }}$ is the area of annulus between the train and the tunnel $\left(\mathrm{m}^{2}\right), A_{\mathrm{T}}$ is the free cross-sectional area of tunnel $\left(\mathrm{m}^{2}\right)$ and $A_{z}$ is the crosssectional area of the train $\left(\mathrm{m}^{2}\right)$.

\section{Numerical simulation}

When a train enters a tunnel, three-dimensional (3D), unsteady, compressive air flow is generated. Therefore, 3D unsteady equations are required to acquire a correct description of the air flow generated by a train in a tunnel. According to Baron et al. (2001), the propagation of air pressure disturbance occurs by means of a plane wave in a tunnel when the length of the tunnel is much larger than the hydraulic diameter of the cross-section of the tunnel. Additionally, the instantaneous distribution of fluid dynamics variables becomes uniform in tunnel sections (Baron et al., 2001). In 3D analyses, 3D features are focused in regions close to the train, tunnel portals and tunnel crosssections of complex shape (Mossi and Sibilla, 2002). According to Mossi and Sibilla (2002), quasi-1D models can reasonably predict the large-scale behaviour of air flow in a tunnel with a high-speed train passing through, and 1D models that can provide sufficiently accurate explanations of experimental data have been developed (Muelas et al., 2008). Ricco et al. (2007) used 1D analysis to simulate air flow due to a high-speed train in a tunnel.

It was therefore considered reasonable to predict the behaviour of air flow in a long tunnel by means of quasi-1D analysis, and numerical simulations using Thermotun software were carried out to estimate the traction power demand of a highspeed train running in a tunnel. Thermotun employs the 1D method of characteristics to calculate the effect of air pressure in a tunnel by solving equations of $1 \mathrm{D}$, unsteady, compressible flow in tunnel networks (Tarada et al., 2007). The purpose of the numerical simulations carried out in the current study was to estimate traction power demand and investigate how pressure-relief ducts can decrease the traction power demand of a high-speed train. The traction power demand was investigated with respect to various parameters, including train operation in a twin-tube tunnel, train velocity, a change from a twin-tube to a single-tube tunnel, the free cross-sectional area of a tunnel, the space between pressure-relief ducts, the crosssectional area of the pressure-relief duct and the impact of a single crossover in the middle of a tunnel. The parameters used in the numerical simulations are listed in Table 1. The tunnel parameters were based on the preliminary design for MokpoJeju subsea tunnel in South Korea and the train used in the simulation was based on the KTX-II Sancheon, which is a currently operating high-speed train in South Korea.

\subsection{Modelling of the tunnel and train}

Quasi-1D numerical simulations were carried out on a railway network with tunnels and pressure-relief ducts. The simulations involved two running tunnels with a cross-sectional area of $60 \mathrm{~m}^{2}$ and length of $35000 \mathrm{~m}$, set $30 \mathrm{~m}$ apart from each other. Pressure-relief ducts connected the two tunnels with varying distances $(250-300 \mathrm{~m})$ between the ducts. Details of the modelling scheme are presented in Figure 1 and summarised in Table 1. As shown in Table 1, the skin friction factor of the tunnel was assumed to be 0.06 and air pressure outside the

Table 1. Parameters used in the numerical simulations

\begin{tabular}{|c|c|}
\hline & Value \\
\hline \multicolumn{2}{|l|}{ Train parameters } \\
\hline Shape of head & Hypothetical \\
\hline Length, $L_{\text {train }}: m$ & 201 \\
\hline Cross-sectional area, $A_{\text {train }}: \mathrm{m}^{2}$ & $9 \cdot 34$ \\
\hline Perimeter, $P_{\text {train }}: m$ & $11 \cdot 67$ \\
\hline Maximum speed, $V_{\text {train }}: \mathrm{km} / \mathrm{h}$ & 350 \\
\hline Time constant of pressure tightness, $\tau$ : $\mathrm{s}$ & 18 \\
\hline Longitudinal friction factor, $f_{\text {train }}$ & 0.003 \\
\hline Nose and tail loss coefficients & $k_{\text {nose }}=0.05, k_{\text {tail }}=0.07$ \\
\hline \multicolumn{2}{|l|}{ Tunnel parameters } \\
\hline Length, $L_{\text {tun }}: m$ & 35000 \\
\hline Type & Twin-tube, single-track \\
\hline Cross-sectional area, $A_{\text {tun }}: \mathrm{m}^{2}$ & $42 \cdot 59,57 \cdot 25$ \\
\hline Perimeter, $P_{\text {tun }}: \mathrm{m}$ & $31 \cdot 5$ \\
\hline $\begin{array}{l}\text { Tunnel friction factor } \\
\text { (Darcy-Weisbach definition), } \lambda_{\text {tun }}\end{array}$ & 0.024 \\
\hline Skin friction factor, $f_{\text {tun }}$ & 0.06 \\
\hline $\begin{array}{l}\text { Cross-sectional area of } \\
\text { pressure-relief duct, } A_{\text {rd }}: \mathrm{m}^{2}\end{array}$ & $0 \cdot 7,1,2,3 \cdot 14$ \\
\hline $\begin{array}{l}\text { Distance between pressure-relief } \\
\text { ducts, } S_{\text {rd }}: m\end{array}$ & $250,275,300$ \\
\hline Length of pressure-relief duct, $L_{r d}: m$ & 30 \\
\hline Inclination: \% & 0 \\
\hline $\begin{array}{l}\text { Ambient tunnel air, ground, tunnel wall } \\
\text { and train wall temperature: }{ }^{\circ} \mathrm{C}\end{array}$ & 15 \\
\hline Normal pressure at sea level: Pa & 101300 \\
\hline
\end{tabular}




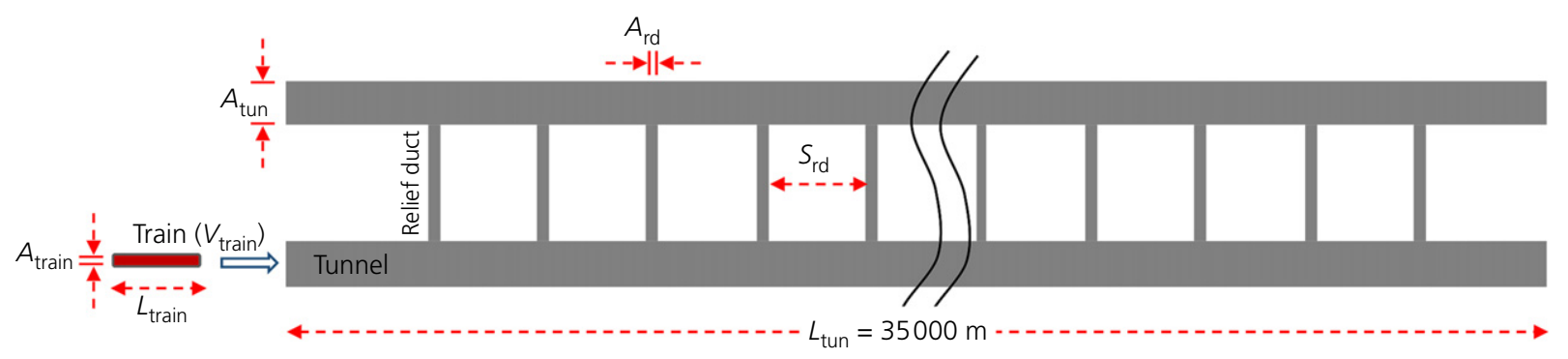

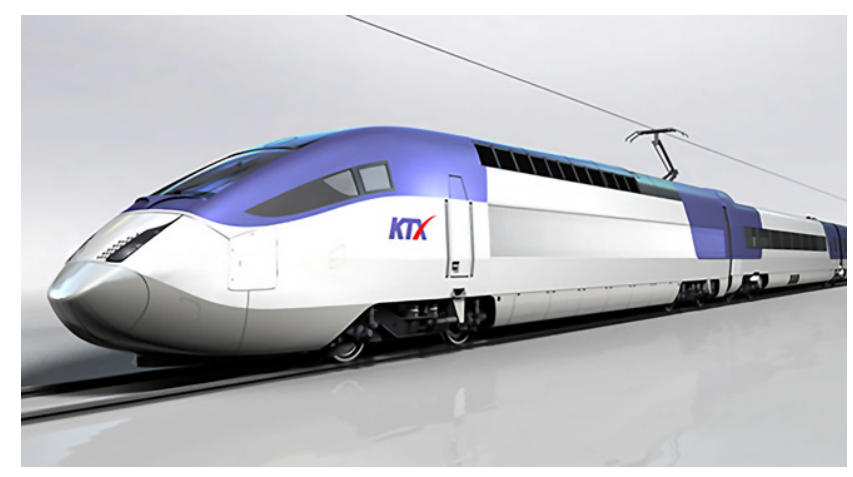

Figure 2. KTX-II Sancheon train

tunnel was set equal to normal pressure at sea level of $101300 \mathrm{~Pa}$. The tunnel was horizontal and the ambient temperature and the temperature inside the tunnel and on the tunnel wall was fixed at $15^{\circ} \mathrm{C}$.

The geometry and dimensions of the train model were based on the KTX-II Sancheon (Figure 2), a high-speed passenger train developed in South Korea that can reach a cruise speed of $330 \mathrm{~km} / \mathrm{h}$. The train model used in the numerical simulations had a hypothetical streamlined head shape, a length of $201 \mathrm{~m}$, a perimeter of $11.67 \mathrm{~m}$ and a cross-sectional area of $9 \cdot 34 \mathrm{~m}^{2}$ (Table 1). The pressure tightness coefficient of the train is $18 \mathrm{~s}$ according to information from the locomotive manufacturer (Lee et al., 2013). The longitudinal friction factor on the train was set at 0.003 , and the nose and tail loss coefficients were 0.05 and $0 \cdot 07$, respectively.

\subsection{Simulation cases}

To investigate the effects of tunnel pressure-relief ducts, 25 different simulations were carried out (Table 2). In the simulations, one train moved in a single tunnel at a speed of $350 \mathrm{~km} / \mathrm{h}$ (the Mokpo-Jeju subsea tunnel aims to operate high-speed trains at this speed). The cross-sectional area of the tunnel ranged from $42.59 \mathrm{~m}^{2}$ (the cross-sectional area of the Channel tunnel) to $57 \cdot 25 \mathrm{~m}^{2}$ (the preliminary design of the Mokpo-Jeju subsea tunnel). The spacing and cross-sectional area of pressure-relief ducts is a critical factor that influences both air pressure alleviation and construction costs. In the simulations, the duct spacing was set at $250 \mathrm{~m}$, $275 \mathrm{~m}$ or $300 \mathrm{~m}$ and the cross-sectional area of the ducts was also varied $\left(0 \cdot 7,1,2\right.$ and $\left.3 \cdot 14 \mathrm{~m}^{2}\right)$. As a reference case, simulation case 25 was for a single tunnel without any pressurerelief ducts.

\section{Results}

As already mentioned, traction demand is the power required to operate locomotives and it is essential to estimate traction demand in the design stage in order to determine the most appropriate design of pressure-relief systems. The results of the 1D simulations showed that pressure-relief ducts have a significant effect on reducing the traction power demand of highspeed trains in tunnels. The aerodynamic traction power required for train passage through the tunnel was calculated along the distance from the tunnel entrance. As clearly shown in Figure 3, there is a close relationship between traction power demand and the presence of pressure-relief ducts. Aerodynamic traction power demand increased with a decrease in the area of the tunnel or the pressure-relief duct. In addition, the figure reveals that traction power demand was inversely proportional to the distance between the pressure-relief ducts because the number of pressure-relief ducts decreases as the spacing increases. Table 3 shows the average traction power demands as calculated from the 1D numerical simulations.

\subsection{Effect of duct cross-sectional area and distance between pressure-relief ducts}

Figures 4-15 show the traction power demand for the train's passage through a tunnel of cross-sectional area $42.59 \mathrm{~m}^{2}$. Simulation cases 1, 2 and 3 (Figures 4-6) were for a pressurerelief duct cross-sectional area of $0.7 \mathrm{~m}^{2}$. In the three cases, the distance between the ducts was set at $250 \mathrm{~m}, 275 \mathrm{~m}$ and $300 \mathrm{~m}$, respectively. Figures 4-6 show that traction demand increased with increasing distance between the pressure-relief ducts because the number of ducts increases as the distance between ducts decreases. For a duct cross-sectional area of $0.7 \mathrm{~m}^{2}$, compared with a duct separation of $250 \mathrm{~m}$, the traction power demand increased by $0 \cdot 5 \%$ for a $275 \mathrm{~m}$ duct separation and by 
Effect of pressure-relief ducts on traction demand in a tunnel: a numerical evaluation

$\mathrm{SeO}$ and $\mathrm{Ha}$

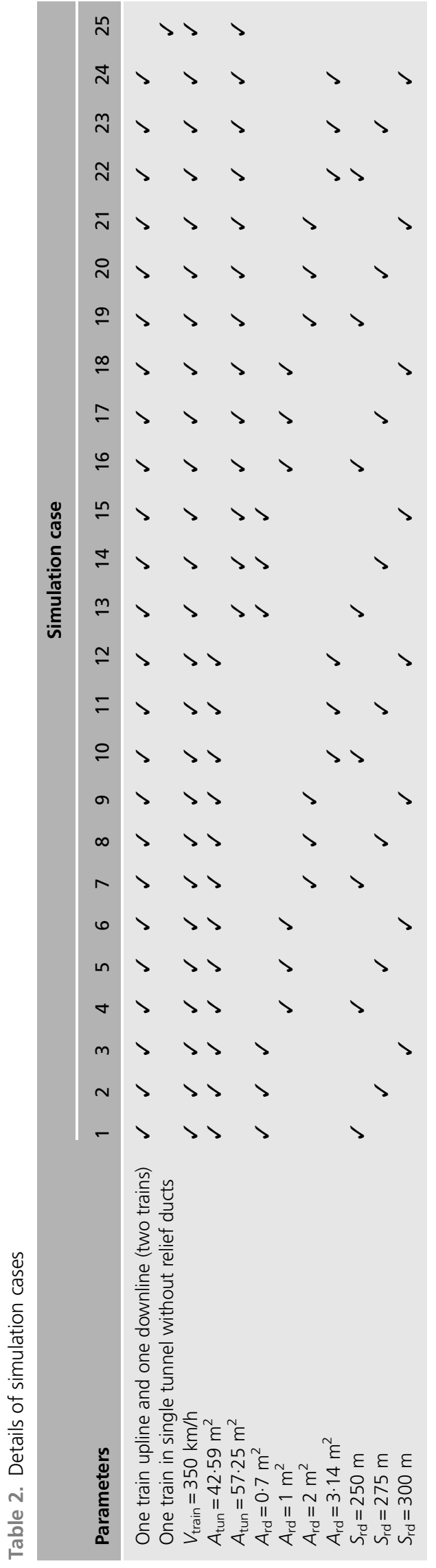

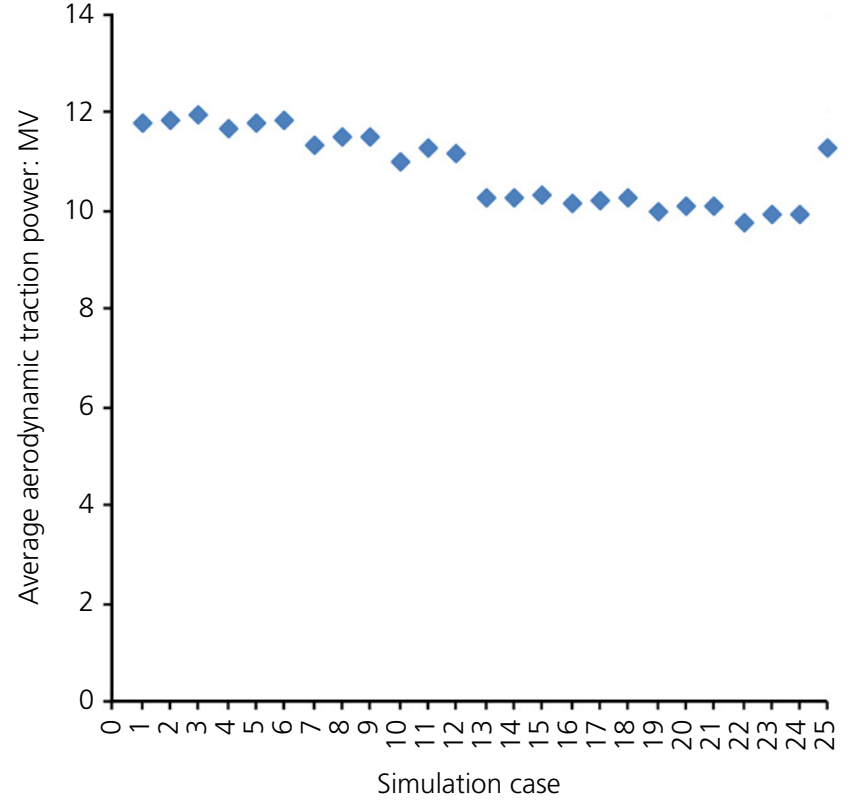

Figure 3. Aerodynamic traction calculated from numerical simulations

Table 3. Average traction power demand during the passage of train through the tunnel

\begin{tabular}{|cccc|}
$\begin{array}{l}\text { Simulation } \\
\text { case }\end{array}$ & $\begin{array}{c}\text { Average } \\
\text { traction power } \\
\text { demand: } \mathbf{M W}\end{array}$ & $\begin{array}{c}\text { Simulation } \\
\text { case }\end{array}$ & $\begin{array}{c}\text { Average } \\
\text { traction power } \\
\text { demand: MW }\end{array}$ \\
\hline 1 & 11.80 & 13 & $10 \cdot 25$ \\
2 & 11.86 & 14 & $10 \cdot 28$ \\
3 & 11.97 & 15 & $10 \cdot 35$ \\
4 & 11.68 & 16 & $10 \cdot 18$ \\
5 & 11.77 & 17 & $10 \cdot 23$ \\
6 & 11.86 & 18 & $10 \cdot 29$ \\
7 & 11.33 & 19 & $9 \cdot 99$ \\
8 & 11.51 & 20 & $10 \cdot 08$ \\
9 & 11.53 & 21 & $10 \cdot 10$ \\
10 & 10.99 & 22 & $9 \cdot 79$ \\
11 & 11.27 & 23 & 9.93 \\
12 & 11.20 & 24 & 9.91 \\
& & 25 & 11.31 \\
\hline
\end{tabular}

$1 \cdot 4 \%$ for a $300 \mathrm{~m}$ duct separation. However, the distribution of traction power demand did not change significantly with different duct separations. Similarly, as shown in Figures 7-9, when the cross-sectional area of the duct was $1 \mathrm{~m}^{2}$, the traction power demand increased by $0.8 \%$ when the duct separation was $275 \mathrm{~m}$ and by $1.5 \%$ for a duct separation of $300 \mathrm{~m}$. In summary, for a duct cross-sectional area of $0.7 \mathrm{~m}^{2}$ or $1 \mathrm{~m}^{2}$, traction power demand increased by $0 \cdot 5-1 \cdot 5 \%$ with increasing distance between the ducts. For a duct cross-sectional area of $2 \mathrm{~m}^{2}$, traction power demand increased by $1.6 \%$ for an increase in duct separation from $250 \mathrm{~m}$ to $275 \mathrm{~m}$ and increased by $1.8 \%$ 


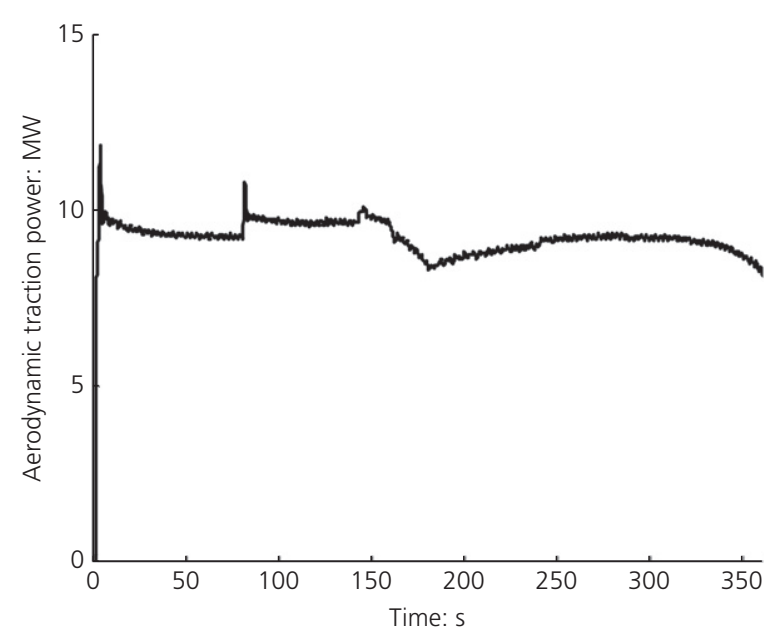

Figure 4. Traction power demand (case 1)

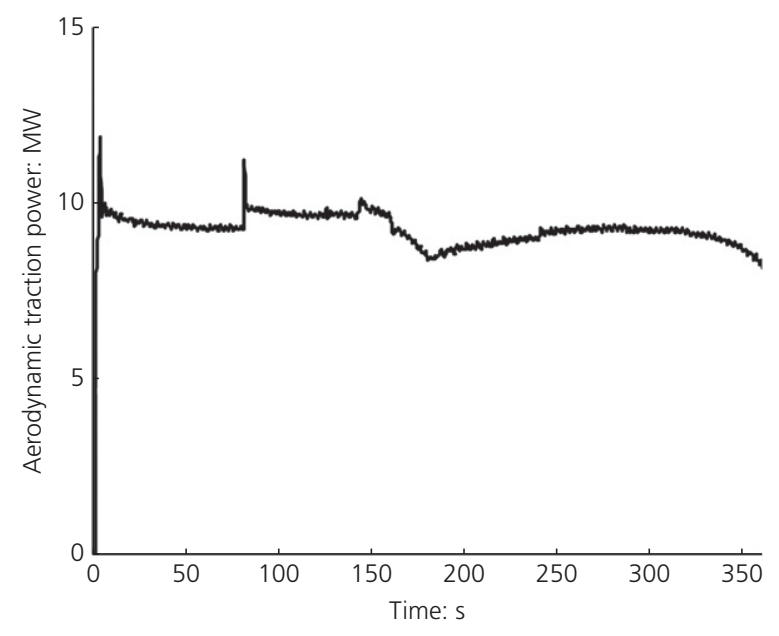

Figure 5. Traction power demand (case 2)

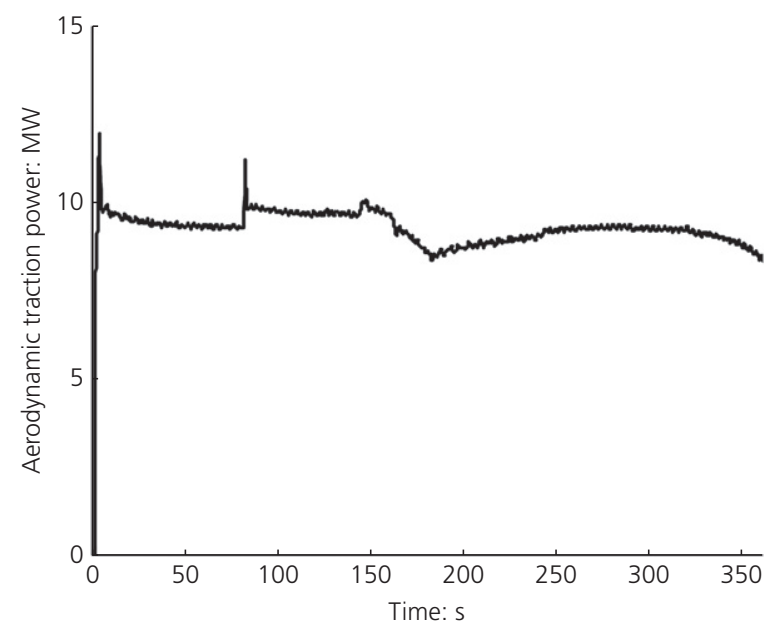

Figure 6. Traction power demand (case 3)

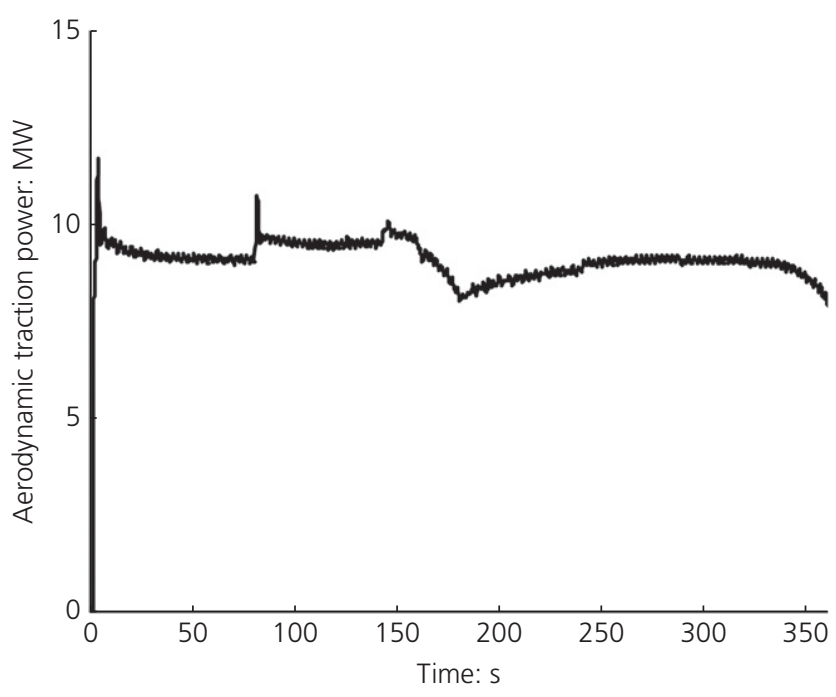

Figure 7. Traction power demand (case 4)

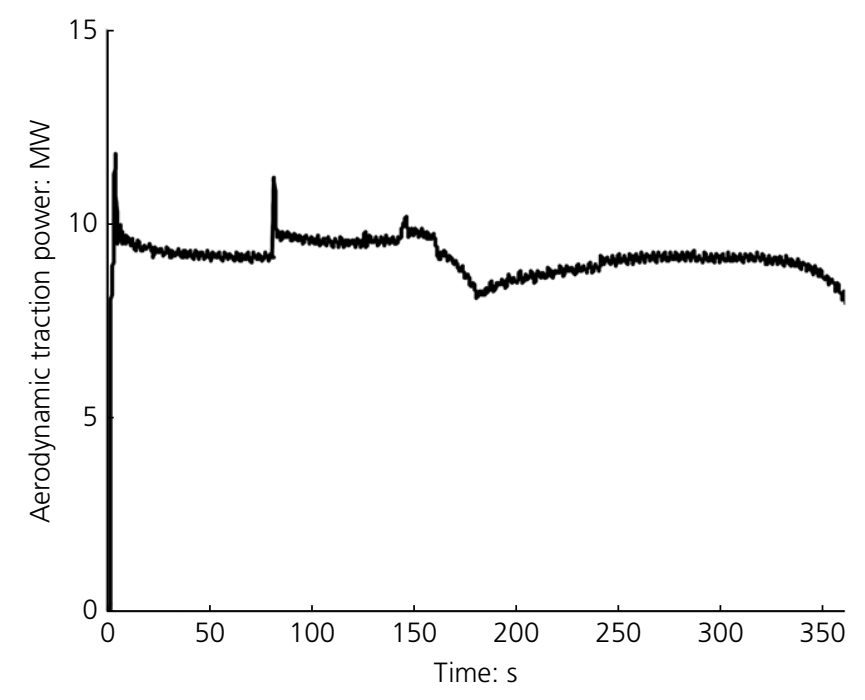

Figure 8. Traction power demand (case 5)

when the duct separation was changed from $250 \mathrm{~m}$ to $300 \mathrm{~m}$ (Figures 10-12). The increase in traction power demand became larger when the cross-sectional area of the duct was $3.14 \mathrm{~m}^{2}$ (Figures 13-15): the increase in traction power demand increased by $2.5 \%$ for an increase in duct separation from $250 \mathrm{~m}$ to $275 \mathrm{~m}$ and by $1.9 \%$ from $250 \mathrm{~m}$ to $300 \mathrm{~m}$.

Figures 16-27 show the traction power demand for the train's passage through a tunnel of cross-sectional area $57 \cdot 25 \mathrm{~m}^{2}$. The trends in traction power demand distribution are similar to those for a tunnel cross-sectional area of $42.59 \mathrm{~m}^{2}$, with traction power demand increasing as the distance between ducts was increased for the same duct crosssectional area. As shown in Figures 16 and 17, for a duct 
Effect of pressure-relief ducts on traction demand in a tunnel: a numerical evaluation $\mathrm{SeO}$ and $\mathrm{Ha}$

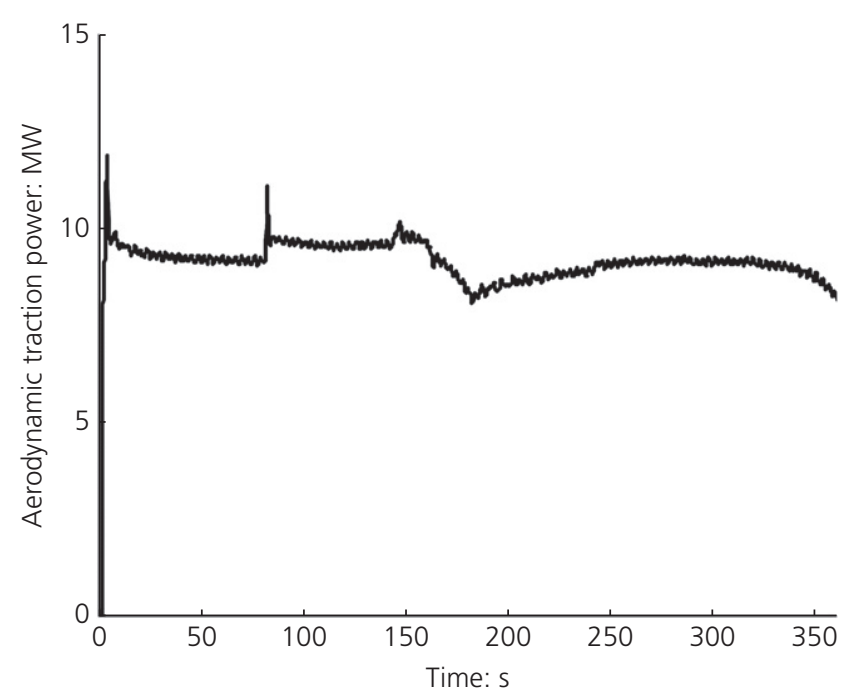

Figure 9. Traction power demand (case 6)

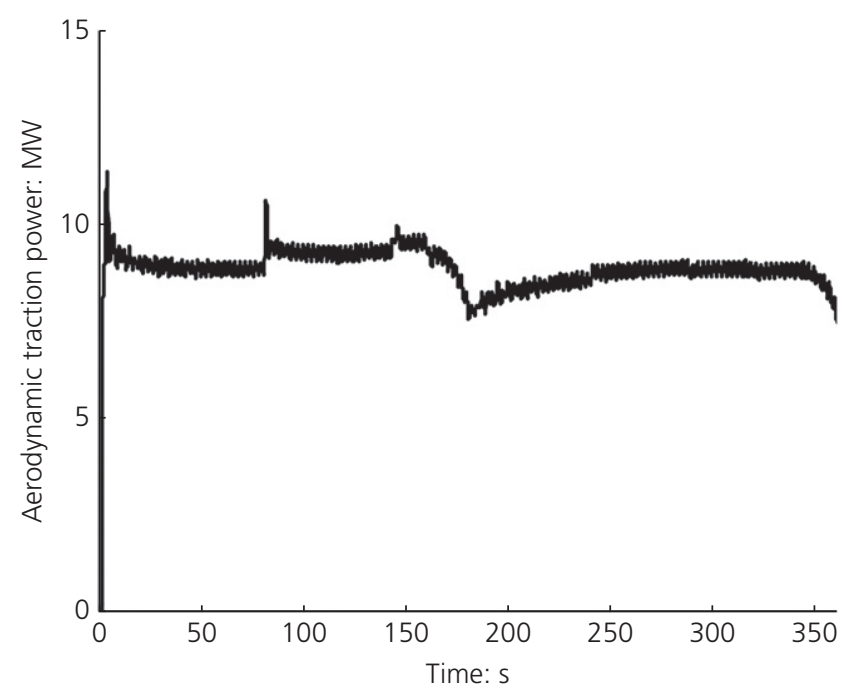

Figure 10. Traction power demand (case 7)

cross-sectional area of $0.7 \mathrm{~m}^{2}$, traction power demand increased slightly from $10 \cdot 25 \mathrm{MW}$ to $10 \cdot 28 \mathrm{MW}$ when distance between the ducts was changed from $250 \mathrm{~m}$ to $275 \mathrm{~m}$. For the same duct area but with an increase in duct separation to $300 \mathrm{~m}$, the traction power demand increased by $1 \%$, from 10.25 MW to $10 \cdot 35 \mathrm{MW}$ (Figures 16 and 18). For a duct cross-sectional area of $1 \mathrm{~m}^{2}$, the traction power demand increased by $0.5 \%$ when the duct separation was increased from $250 \mathrm{~m}$ to $275 \mathrm{~m}$ and by $1 \cdot 1 \%$ for an increase from $250 \mathrm{~m}$ to $300 \mathrm{~m}$ (Figures 19-21). Similarly, as shown in Figures 22-24, traction power demand increased by $0.9 \%$ and $1 \cdot 1 \%$ with increasing distance between the pressure-relief ducts when the duct cross-sectional area was $2 \mathrm{~m}^{2}$. For a duct crosssectional area of $3 \cdot 14 \mathrm{~m}^{2}$ (Figures 25-27), the increase in

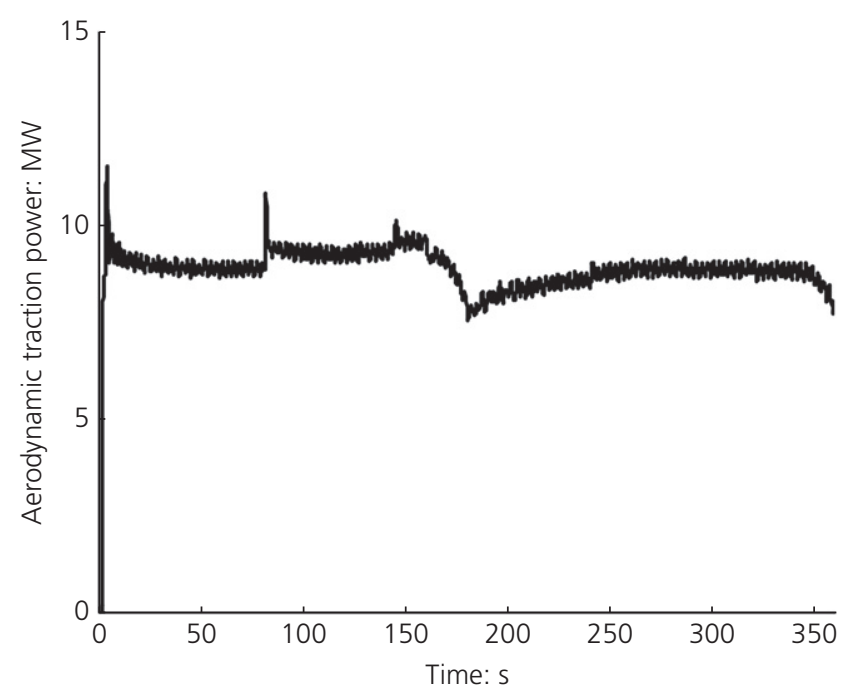

Figure 11. Traction power demand (case 8)

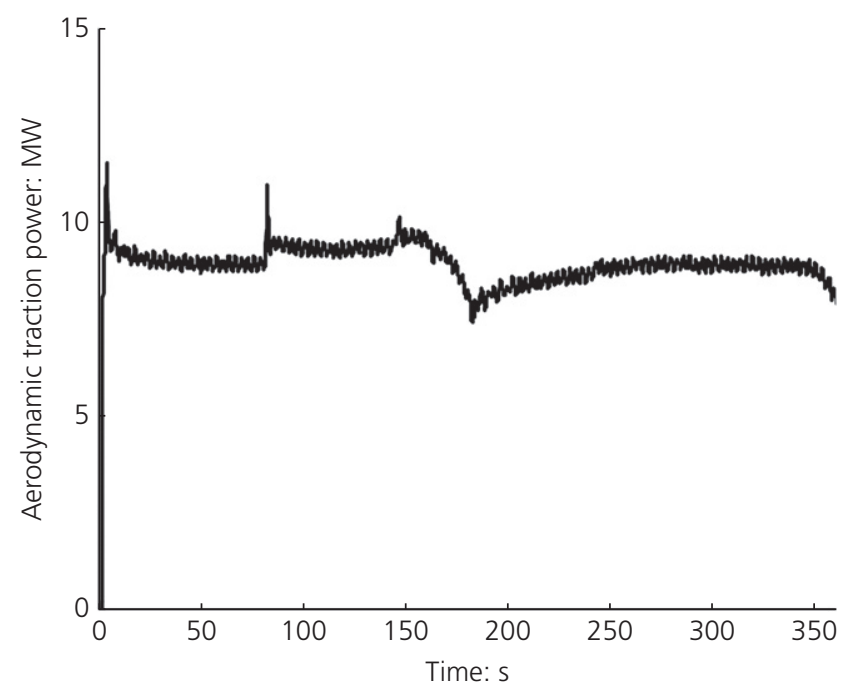

Figure 12. Traction power demand (case 9)

traction power demand with increasing duct separation distance to $275 \mathrm{~m}$ and $300 \mathrm{~m}$ was slightly increased, by $1.4 \%$ and $1 \cdot 2 \%$, respectively.

When the distance between the pressure-relief ducts was held constant, traction power demand was inversely proportional to the cross-sectional area of the duct. For a duct separation of $250 \mathrm{~m}$, comparing simulation case $1\left(A_{\mathrm{rd}}=0.7 \mathrm{~m}^{2}\right)$ and case 4 $\left(A_{\mathrm{rd}}=1 \mathrm{~m}^{2}\right)$, the traction power demand decreased from 1.80 MW to $1.68 \mathrm{MW}$ (Figures 4 and 7). Similarly, when the duct separation was $275 \mathrm{~m}$, traction power demand decreased with an increase in duct cross-sectional area from $0.7 \mathrm{~m}^{2}$ to $1 \mathrm{~m}^{2}$, from $11.86 \mathrm{MW}$ to $11.77 \mathrm{MW}$, respectively, and from $11.97 \mathrm{MW}$ to $11.86 \mathrm{MW}$ when the duct separation was $300 \mathrm{~m}$. 


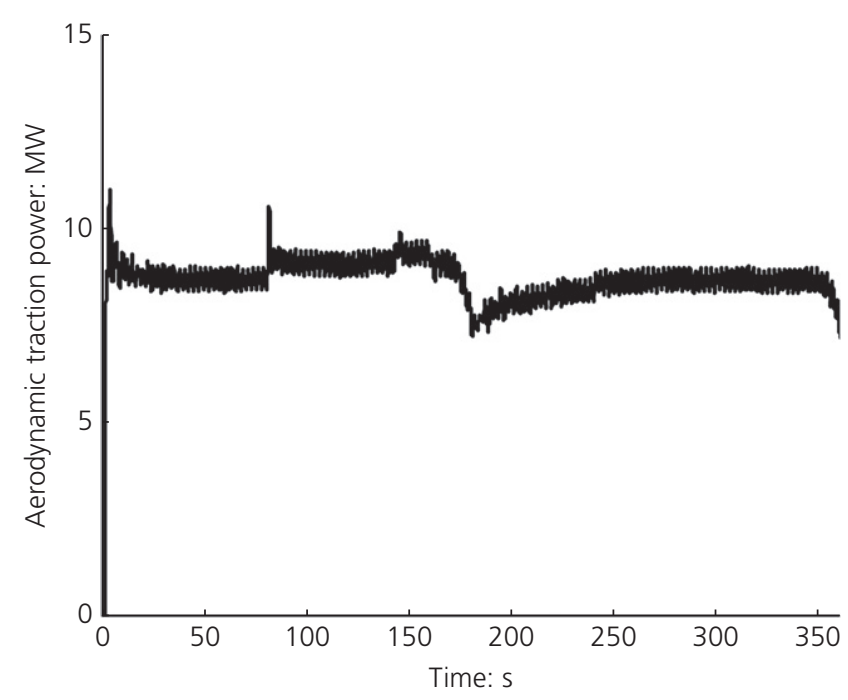

Figure 13. Traction power demand (case 10)

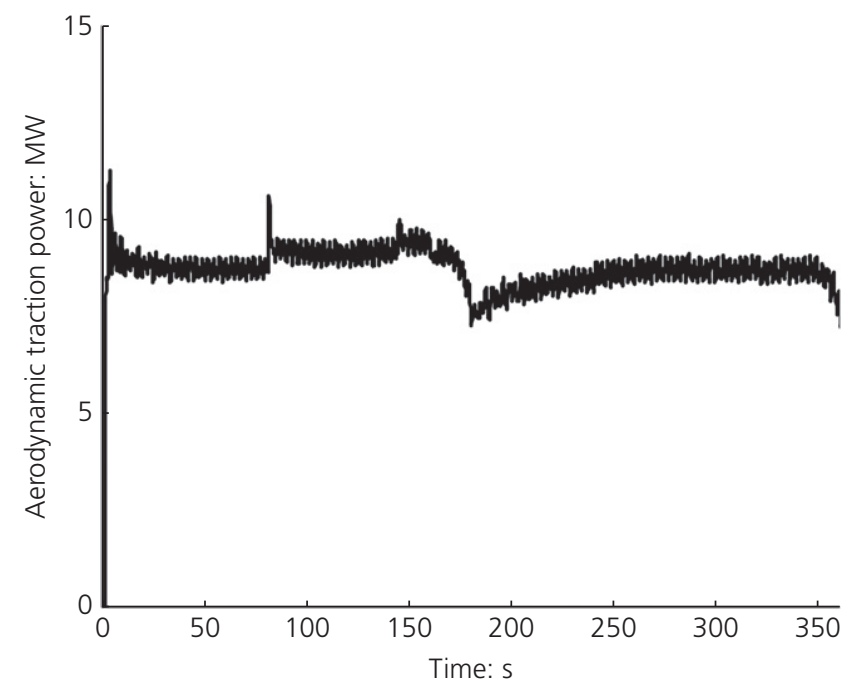

Figure 14. Traction power demand (case 11)

The traction power demand with a constant duct separation also decreased with an increase in duct cross-sectional area from $0.7 \mathrm{~m}^{2}$ to $2 \mathrm{~m}^{2}$ : comparing simulation case 1 and case 7 $\left(S_{\mathrm{rd}}=250 \mathrm{~m}\right)$, case 2 and case $8\left(S_{\mathrm{rd}}=275 \mathrm{~m}\right)$ and case 3 and case $9\left(S_{\mathrm{rd}}=300 \mathrm{~m}\right)$, traction power demands decreased by $4 \cdot 0 \%, 3 \cdot 0 \%$ and $3 \cdot 7 \%$, respectively. With the largest dust crosssectional area of $3 \cdot 14 \mathrm{~m}^{2}$ (cases 10 to 12 ), the traction power demand reduced by $6 \cdot 9 \%, 5 \cdot 0 \%$ and $6 \cdot 4 \%$ compared with comparative cases for the smallest duct cross-sectional area $\left(0.7 \mathrm{~m}^{2}\right)$.

Cases 1 to 12 were for a tunnel cross-sectional area of $42.59 \mathrm{~m}^{2}$ whereas simulation cases 13 to 25 were for a tunnel

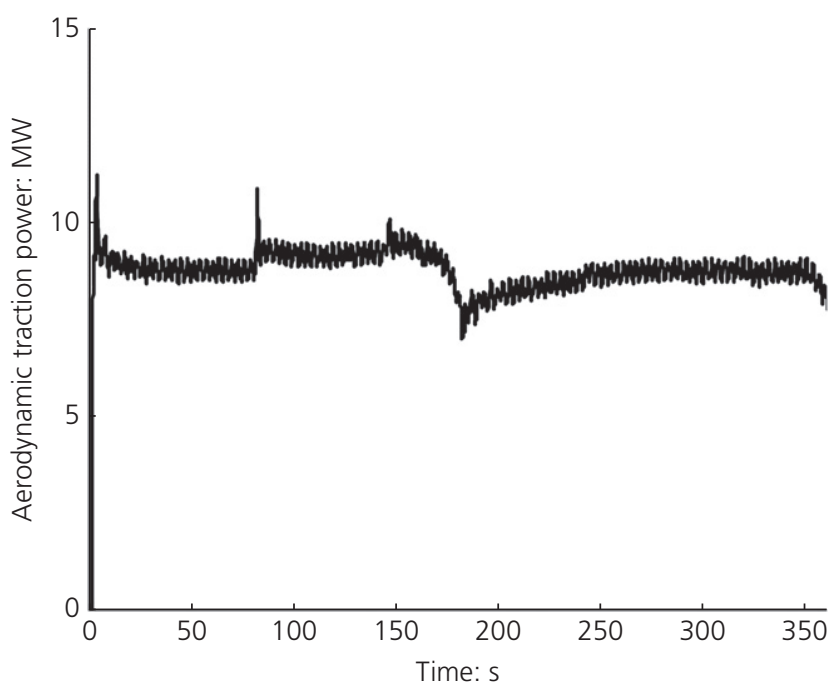

Figure 15. Traction power demand (case 12)

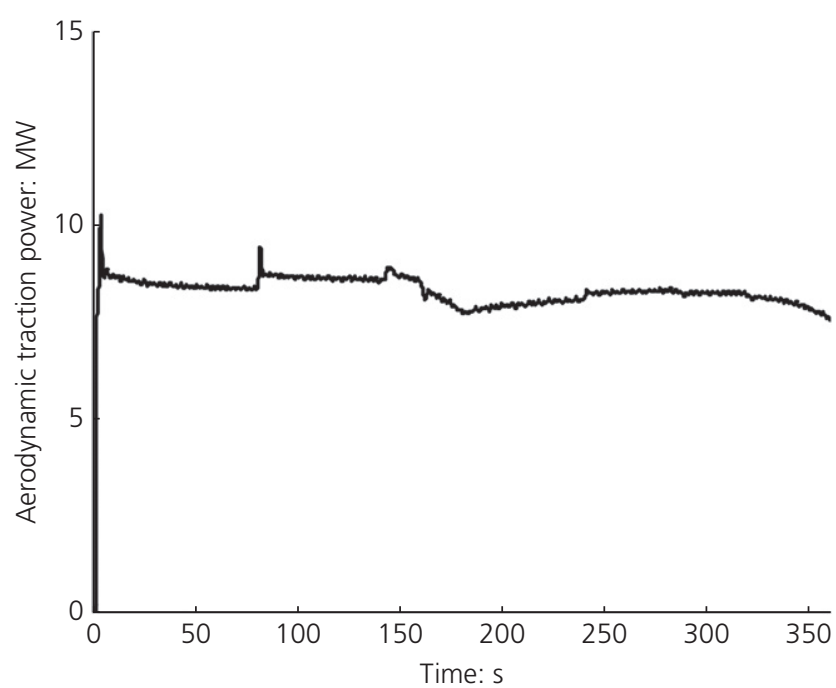

Figure 16. Traction power demand (case 13)

cross-sectional area of $57.25 \mathrm{~m}^{2}$. For the latter tunnel area, as the duct cross-sectional area was changed from $0.7 \mathrm{~m}^{2}$ to $1 \mathrm{~m}^{2}$, the traction power demand decreased by $0.7 \%$ for a duct separation of $250 \mathrm{~m}$, by $0.5 \%$ for a duct separation of $275 \mathrm{~m}$ and by $0.6 \%$ for a duct separation of $300 \mathrm{~m}$. According to simulation cases 19 to 21 , the decrease in traction power demand slightly increased with increasing duct cross-sectional area from $0.7 \mathrm{~m}^{2}$ to $2 \mathrm{~m}^{2}$. For a change in duct cross-sectional area from $0.7 \mathrm{~m}^{2}$ to $3.14 \mathrm{~m}^{2}$, traction power demand decreased by $4 \cdot 5 \%$ for $S_{\mathrm{rd}}=250 \mathrm{~m}$, by $3 \cdot 4 \%$ for $S_{\mathrm{rd}}=275 \mathrm{~m}$ and by $4 \cdot 3 \%$ for $S_{\mathrm{rd}}=300 \mathrm{~m}$ (simulation cases 22 , 23 and 24). 


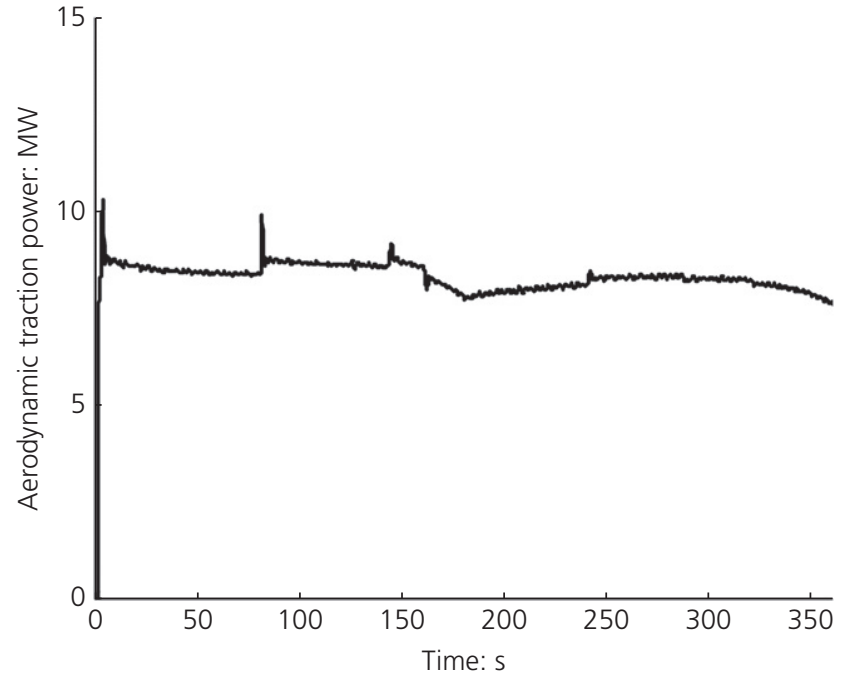

Figure 17. Traction power demand (case 14)

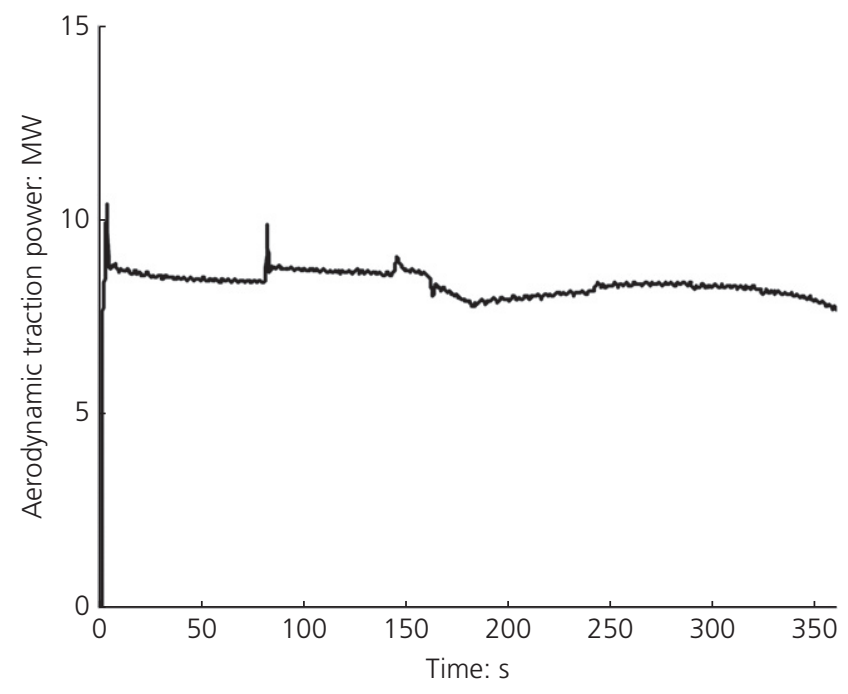

Figure 18. Traction power demand (case 15)

Simulation case 25 was run for a tunnel without any pressurerelief measures. The traction power demand in a single tunnel without a pressure-relief duct was 11.31 MW (Figure 28). Compared with the cases with pressure-relief ducts (cases 13 to 24), it is evident that traction power demand was significantly reduced due to the presence of pressure-relief ducts. Traction power demand decreased by $8 \cdot 5 \%$ when the tunnel was fitted with ducts of area $0.7 \mathrm{~m}^{2}$ and $300 \mathrm{~m}$ spacing. As the free cross-sectional area of a duct increased and the spacing between the ducts decreased, traction power demand was decreased by up to $13.4 \%$, as shown in simulation case 22 for a duct cross-sectional area of $3.14 \mathrm{~m}^{2}$ and $250 \mathrm{~m}$ between the ducts.

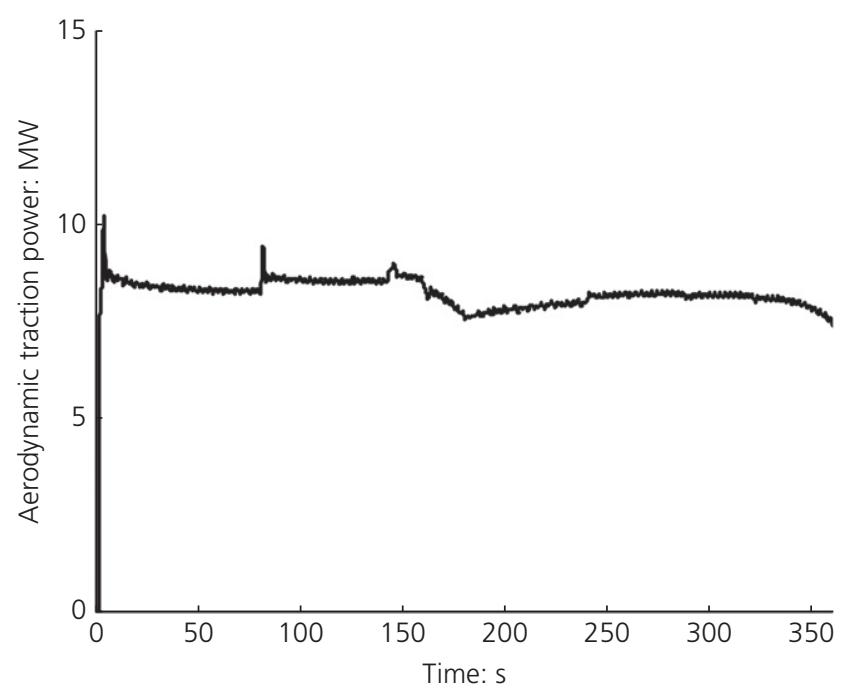

Figure 19. Traction power demand (case 16)

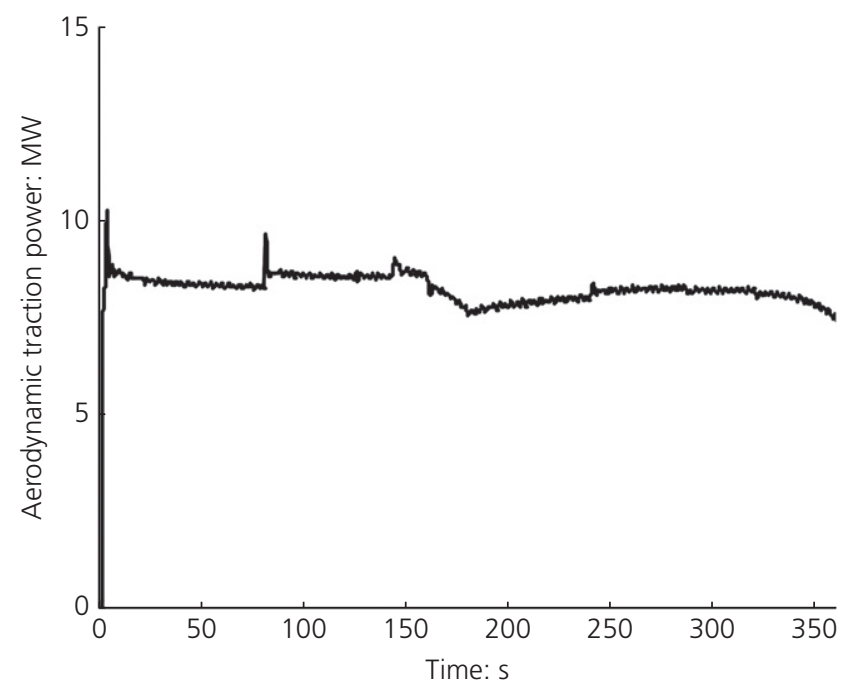

Figure 20. Traction power demand (case 17)

\subsection{Effect of cross-sectional area of tunnel}

As detailed in Table 2, the first 12 simulation cases calculated traction power demand for a tunnel cross-sectional area of $42.59 \mathrm{~m}^{2}$ and the other 13 cases were for a tunnel cross-section of $59.25 \mathrm{~m}^{2}$. In order to investigate the effect of tunnel crosssectional area on the traction power demand, differences in traction power demands for the same cross-sectional area and duct separation were calculated. The results, shown in Table 4, show that the decrease in traction power demand ranged from $10.9 \%$ to $13 \cdot 5 \%$ when the cross-sectional area of the tunnel was increased from $42.59 \mathrm{~m}^{2}$ to $59 \cdot 25 \mathrm{~m}^{2}$. The change in traction power due to a change in cross-sectional area or duct separation was in the range $0 \cdot 3-2 \cdot 5 \%$ and the differences between 


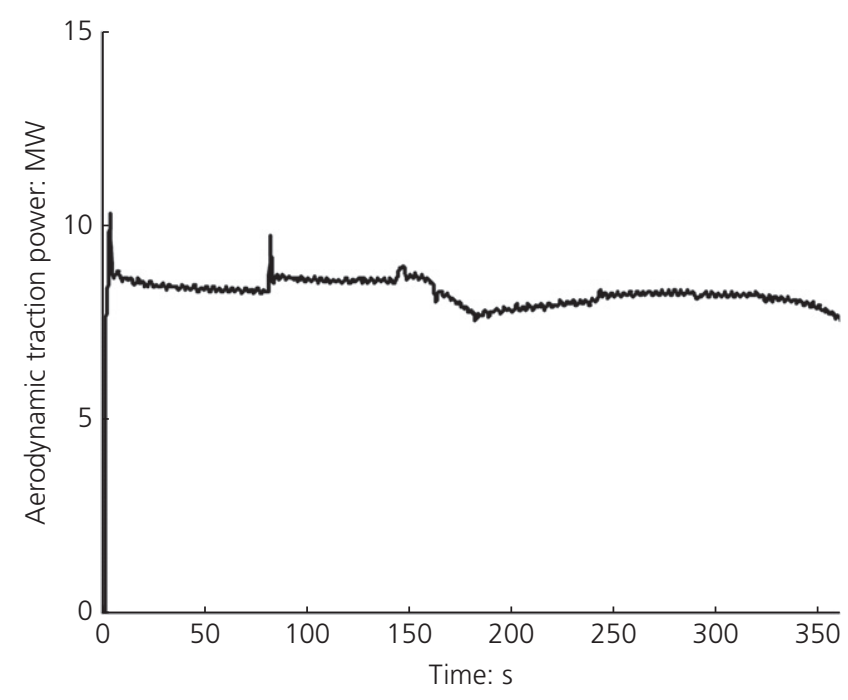

Figure 21. Traction power demand (case 18)

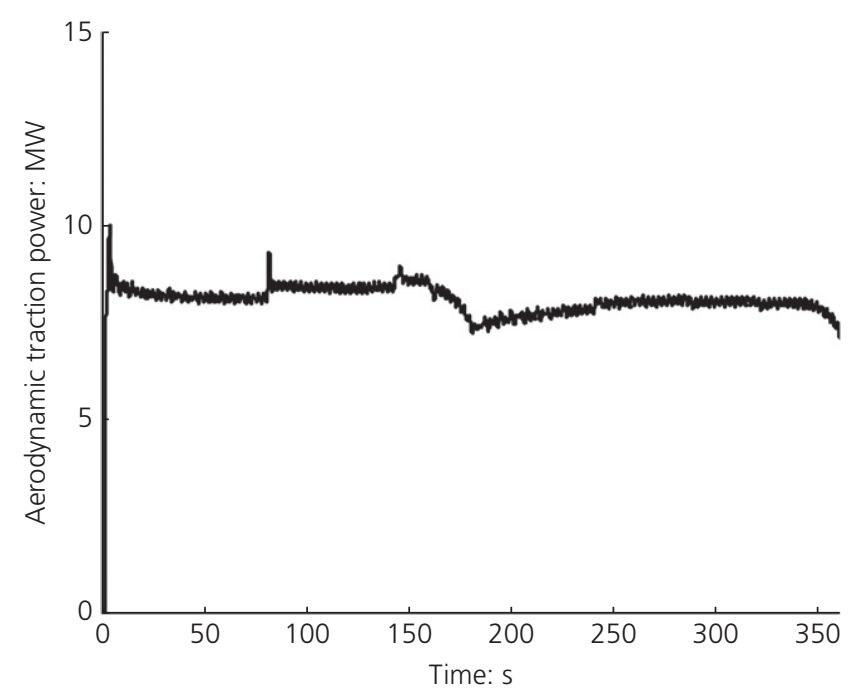

Figure 22. Traction power demand (case 19)

maximum and minimum traction powers were much smaller than those for a change in tunnel cross-sectional area. In other words, the change in traction power demand was larger when the tunnel cross-sectional area was changed in comparison to when the cross-sectional area and distance between ducts were changed. This implies that it is more effective to increase the cross-sectional area of a tunnel in order to alleviate air pressure and decrease traction power demand. However, increasing the cross-sectional area of a tunnel requires a significant increase in construction investment and there are many restrictions on alignment and tunnel depth when the cross-sectional area of a tunnel is changed. Therefore, it could be more efficient to modify the duct cross-sectional area and the distance between

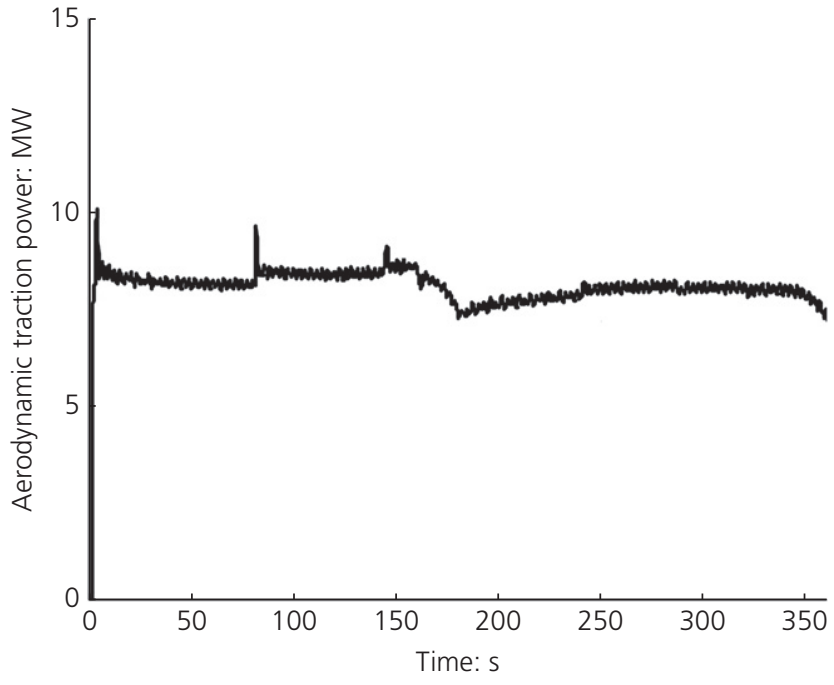

Figure 23. Traction power demand (case 20)

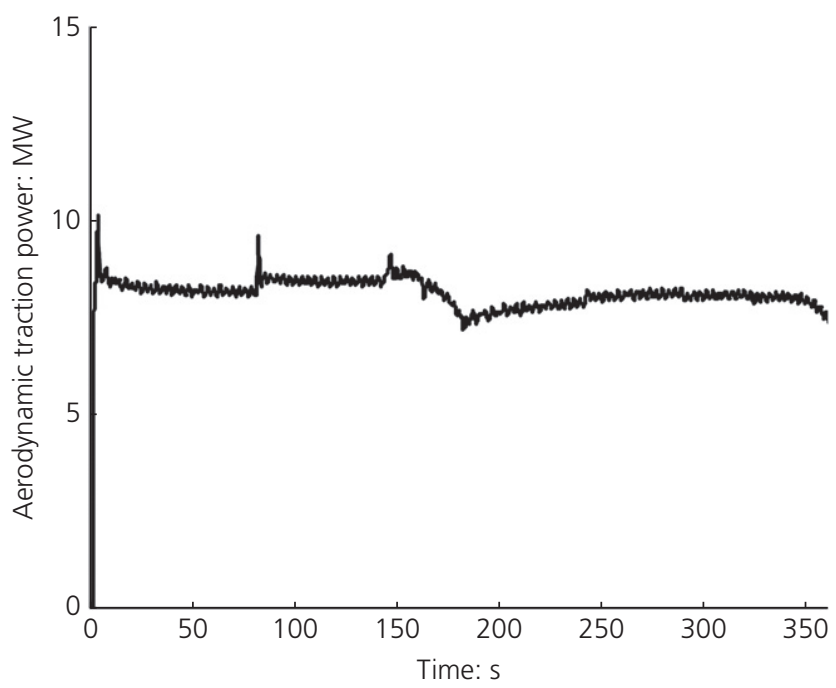

Figure 24. Traction power demand (case 21)

ducts to achieve efficient traction power demands for the operation of high-speed trains in tunnels.

\section{Conclusion}

One-dimensional numerical analyses were carried out based on a subsea tunnel under preliminary design in South Korea. The tunnel is being designed as a twin-tube, single-track system for the operation of high-speed trains running at $350 \mathrm{~km} / \mathrm{h}$. A number of simulation cases were considered in order to investigate the effect of a pressure-relief system. In total, 25 simulation cases were conducted, considering different values of the free cross-sectional area of the tunnel, the free cross-sectional area of pressure-relief ducts and the distance 
Effect of pressure-relief ducts on traction demand in a tunnel: a numerical evaluation $\mathrm{SeO}$ and $\mathrm{Ha}$

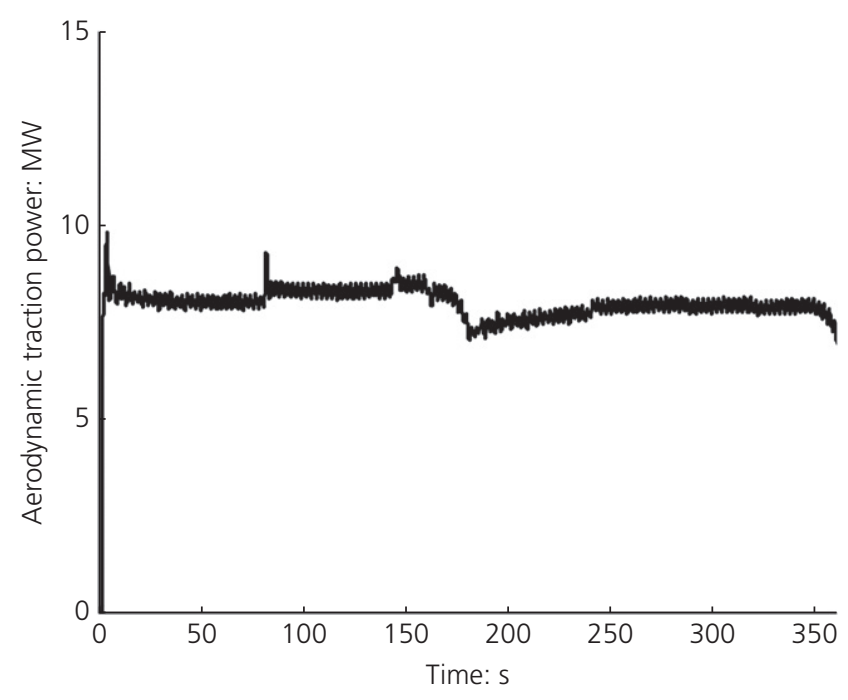

Figure 25. Traction power demand (case 22)

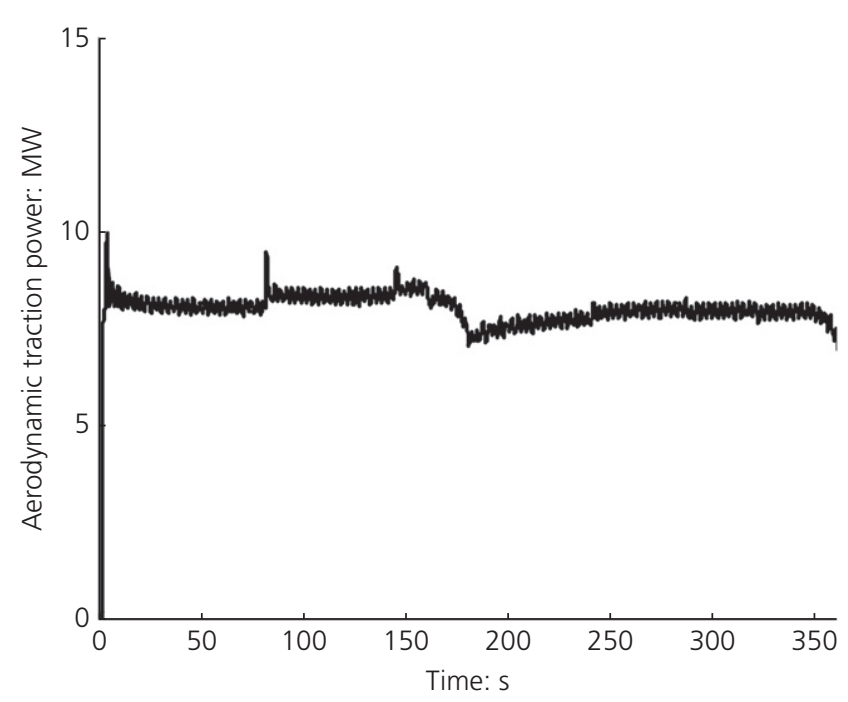

Figure 26. Traction power demand (case 23)

between ducts. Traction power demands were calculated and shown to have a very close relationship with the existence of pressure-relief ducts. The following conclusions were drawn from this study.

- The free cross-sectional areas of both the tunnel and the pressure-relief ducts are closely related to the aerodynamic conditions and traction power demand of a train in a tunnel. As the free cross-sectional area of a duct decreases, traction power demand increases because aerodynamic drag and resistance increase with a smaller duct area. In other words, traction power demand is inversely proportional to the free cross-sectional area of pressurerelief ducts for a constant distance between ducts.

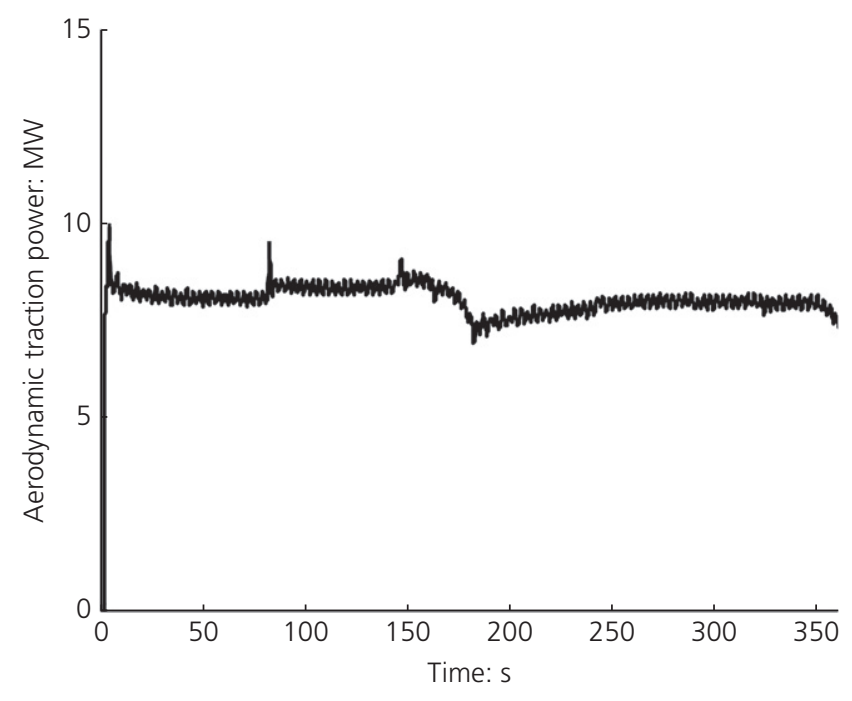

Figure 27. Traction power demand (case 24)

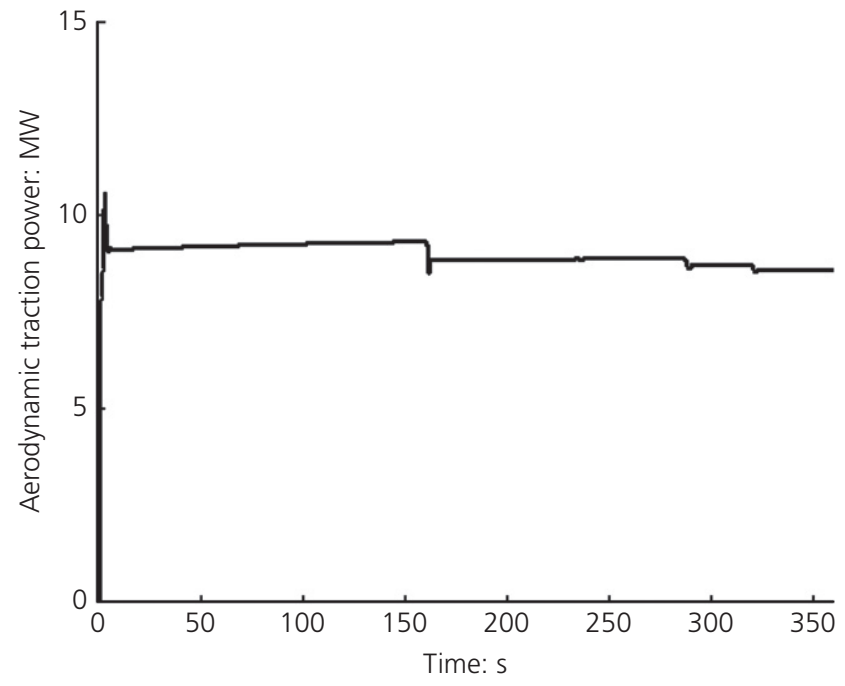

Figure 28. Traction power demand (case 25)

Table 4. Effect of tunnel cross-sectional area on traction power demand

\begin{tabular}{lc|} 
Simulation cases & $\begin{array}{c}\text { Difference in aerodynamic } \\
\text { traction demand: \% }\end{array}$ \\
\hline Case 1 and case 13 & $-13 \cdot 1$ \\
Case 2 and case 14 & $-13 \cdot 3$ \\
Case 3 and case 15 & $-13 \cdot 5$ \\
Case 4 and case 16 & $-12 \cdot 8$ \\
Case 5 and case 17 & $-13 \cdot 1$ \\
Case 6 and case 18 & $-13 \cdot 2$ \\
Case 7 and case 19 & $-11 \cdot 8$ \\
Case 8 and case 20 & $-12 \cdot 4$ \\
Case 9 and case 21 & $-12 \cdot 4$ \\
Case 10 and case 22 & $-10 \cdot 9$ \\
Case 11 and case 23 & $-11 \cdot 9$ \\
Case 12 and case 24 & $-11 \cdot 5$ \\
\hline
\end{tabular}


The presence of pressure-relief ducts has a significant influence on reducing the traction power demand of a high-speed train in a tunnel. For the same free cross-sectional area of a duct, the distance between ducts governs the amount of traction power demand. Traction power demand increases as the distance between ducts increases. Thus, traction power demand is proportional to the distance between ducts because the number of ducts installed in a tunnel is inversely proportional to the distance between them.

- The traction power demand decreases significantly with an increase in the free cross-sectional area of the tunnel. Traction power demand could be decreased by $12 \cdot 5 \%$ with an increase in tunnel cross-sectional area from $42.59 \mathrm{~m}^{2}$ to $57.25 \mathrm{~m}^{2}$. In comparison, traction power demand decreased by just $0 \cdot 3-2 \cdot 5 \%$ when the distance between the ducts was changed and by $0 \cdot 3-4 \cdot 5 \%$ when the cross-sectional area of the duct was changed. However, increasing the cross-sectional area of a tunnel requires a significant increase in construction cost. Hence, it could be more efficient to modify the cross-sectional area and distance between ducts in order to achieve the most efficient traction power demand for the operation of high-speed trains in a tunnel.

Further research is needed to validate the results obtained in this study. A 1:50 scale KTX-II train and Mokpo-Jeju subsea tunnel have been built at the Korean Institute of Construction Technology in South Korea. The experimental model includes twin-tube tunnels with detachable pressure-relief ducts, acceleration system, braking system, control and data acquisition system. This physical system was prepared for a research project entitled 'Development of key subsea tunnelling technology' and is being used to validate the results of the numerical analyses performed in this study. Physical tests are currently being performed for various test cases and the simulation cases presented in this paper. The results from the physical tests will be thoroughly examined and used to assess the effect of pressure-relief ducts obtained using quasi-1D numerical simulations.

\section{Acknowledgement}

This research was supported by a grant (project 15SCIPB066321-03 (Development of key subsea tunnelling technology)) from the Infrastructure and Transportation Technology Promotion Research Program funded by the Ministry of Land, Infrastructure and Transport of the Korean government.

\section{REFERENCES}

Baron A, Mossi M and Sibilla S (2001) The alleviation of the aerodynamic drag and wave effects of high-speed trains in very long tunnels. Journal of Wind Engineering and Industrial Aerodynamics 89: 365-401.
Barthes H, Bordas A and Bouillot D (1994) Tunnels - special works. In The Channel Tunnel, Part 3: French Section (Fullalove S (ed.)), Thomas Telford, London, UK, pp. 63-75.

Fairbairn AG (1995) Tunnel ventilation, including aerodynamic. In The Channel Tunnel, Part 4: Transport Systems (Fullalove S (ed.)), Thomas Telford, London, UK, pp. 32-41.

Gawthorpe RG (1978) Aerodynamics of trains in the open air. Railway Engineer International 3(3): 7-12.

Gawthorpe RG and Pope CW (1992) Aerodynamic aspects of train design for operation through the Channel tunnel. In Proceedings of the Institution of Mechanical Engineers (IMechE): International Conference on Train Technology for the Tunnel, Le Touquet, France. Institution of Mechanical Engineers, London, UK, paper no. c451/003.

Henson D (1995) Aerodynamics, Ventilation and Cooling the Tunnel. Engineering the Channel Tunnel, 1st edn. E\&FN Spon/Eurotunnel, London, UK.

Howe MS, lida M, Fukuda T and Maeda T (2000) Theoretical and experimental investigation of the compression wave generated by a train entering a tunnel with a flared portal. Journal of Fluid Mechanics 425: 111-132.

Lee H, Kang H, Kim H and Kim H (2013) Analysis of aerodynamic characteristics for the selection of cross-section to the TBM railway tunnels. Journal of Korean Tunnelling and Underground Space Association 15(6): 625-635.

Mossi M and Sibilla S (2002) Swissmetro: Aerodynamic drag and wave effects in tunnels under partial vacuum. Proceedings of the 17th International Conference on Magnetically Levitated Systems and Linear Drives, Lausanne, Switzerland, pp. 156-163.

Muelas AM, Ramiro EV, Cuesta JG and Ruiz JM (2008) Pressure measurements on real high-speed trains travelling through tunnels. Proceedings of BBAA VI International Colloquium on Bluff Bodies Aerodynamics and Applications, Milan, Italy, pp. 2-3.

Qun-Zhan L (2010) On some technical key problems in the development of traction power supply system for high-speed railway in China. Journal of the China Railway Society 4(4): 119-124.

Raghunathan RS, Kim HD and Setoguchi T (2002) Aerodynamics of high-speed railway train. Progress in Aerospace Sciences 38(6): 469-514.

Reinke P and Busslinger A (2011) Improvement of Aero and Thermodynamics of Rail Tunnels by Cross-connections with Shut-off Devices. HBI Haerter Ltd, Berne, Switzerland, pp. $38-43$.

Ricco P, Baron A and Molteni P (2007) Nature of pressure waves induced by a high-speed train travelling through a tunnel. Journal of Wind Engineering and Industrial Aerodynamics 95(8): $781-808$.

Shen Z (2012) The superiorities innovatively developing high-speed train technology in China. Science (China) 57(8): 594-599.

Southwood AJ (1994) The Channel Tunnel: A Designer's Perspective. Mott MacDonald, Croydon, UK.

Tarada F, Himbergen A and Stieltjes I (2007) Aerodynamic loading of trains passing through tunnels. Proceedings of Railway Engineering Conference, London, UK, pp. 20-21.

UIC (International Union of Railways) (1998) Technical Review of Tunnel Pressure Alleviation Devices. European Rail Research Institute, Utrecht, the Netherlands, ERRI Report C 218/RP 4.

UIC (2005) Determination of Railway Tunnel Cross-Sectional Area on the Basis of Aerodynamic Considerations, 2nd edn. UIC, Paris, France, Leaflet 779-11.

Vardy AE (1996a) Aerodynamic drag on trains in tunnels, part 1: synthesis and definitions. Proceedings of the Institute of Mechanical Engineers, Part F: Journal of Rail and Rapid Transit 210(1): 29-38. 
Transport

Volume 172 Issue TR4
Effect of pressure-relief ducts on traction

demand in a tunnel: a numerical evaluation

$\mathrm{SeO}$ and $\mathrm{Ha}$
Vardy AE (1996b) Aerodynamic drag on trains in tunnels, part 2: prediction and validation. Proceedings of the Institute of Mechanical Engineers, Part F. Journal of Rail and Rapid Transit 210(1): 39-49.

Vardy AE and Dayman B (1979) Alleviation of tunnel entry pressure transient: 2 - theoretical modelling and experimental correlation. Proceeding of the 3rd International Symposium on the Aerodynamics and Ventilation of Vehicle Tunnels, BHRA Fluid Engineering, Cranfield, UK, pp. 363-376.
Wood RM (2003) Aerodynamic Drag and Drag Reduction: Energy and Energy Savings. American Institute of Aeronautics and Astronautics, Reno, NV, USA, AIAA Research paper 2003-0209.

Yang M, Du J, Li Z, Huang S and Zhou D (2017) Moving model test of high-speed train aerodynamic drag based on stagnation pressure measurements. PLoS One 12(1): e0169471.

\section{How can you contribute?}

To discuss this paper, please email up to 500 words to the editor at journals@ice.org.uk. Your contribution will be forwarded to the author(s) for a reply and, if considered appropriate by the editorial board, it will be published as discussion in a future issue of the journal.

Proceedings journals rely entirely on contributions from the civil engineering profession (and allied disciplines). Information about how to submit your paper online is available at www.icevirtuallibrary.com/page/authors, where you will also find detailed author guidelines. 